\title{
Acute effect of different antidepressants on glycemia in diabetic and non-diabetic rats
}

R. Gomez, J. Huber, G. Tombini and H.M.T. Barros
Divisão de Farmacologia, Fundação Faculdade Federal de Ciências Médicas de Porto Alegre, Porto Alegre, RS, Brasil

\section{Correspondence \\ H.M.T. Barros \\ Divisão de Farmacologia \\ FFFCMPA \\ Rua Sarmento Leite, 245 \\ 90050-170 Porto Alegre, RS \\ Brasil \\ Fax: + 55-51-224-8822 \\ E-mail: helenbar@fffcmpa.tche.br \\ R. Gomez is the recipient of a CAPES fellowship. H.M.T. Barros \\ is the recipient of a $\mathrm{CNPq}$ \\ Scientific Productivity grant.}

Received M ay 19, 2000

Accepted September 13, 2000

\section{Abstract}

Diabetic patients have a $20 \%$ higher risk of depression than the general population. Treatment with antidepressant drugs can directly interfere with blood glucose levels or may interact with hypoglycemic agents. The treatment of depression in diabetic patients must take into account variations of glycemic levels at different times and a comparison of the available antidepressant agents is important. In the present study we evaluated the interference of antidepressants with blood glucose levels of diabetic and non-diabetic rats. In a first experiment, male adult Wistar rats were fasted for $12 \mathrm{~h}$. Imipramine $(5 \mathrm{mg} / \mathrm{kg})$, moclobemide $(30 \mathrm{mg} / \mathrm{kg})$, clonazepam $(0.25 \mathrm{mg} / \mathrm{kg})$, fluoxetine $(20$ $\mathrm{mg} / \mathrm{kg}$ ) sertraline $(30 \mathrm{mg} / \mathrm{kg})$ or vehicle was administered. After 30 min, fasting glycemia was measured. An oral glucose overload of $1 \mathrm{ml}$ of a $50 \%$ glucose solution was given to rats and blood glucose was determined after 30,60 and $90 \mathrm{~min}$. Imipramine and clonazepam did not change fasting or overload glycemia. Fluoxetine and moclobemide increased blood glucose at different times after the glucose overload. Sertraline neutralized the increase of glycemia induced by oral glucose overload. In the second experiment, non-diabetic and streptozotocininduced diabetic rats were fasted, and the same procedures were followed for estimation of glucose tolerance $30 \mathrm{~min}$ after glucose overload. Again, sertraline neutralized the increase in glycemia after glucose overload both in diabetic and non-diabetic rats. These data raise the question of whether sertraline is the best choice for prolonged use for diabetic individuals, because of its antihyperglycemic effects. Clonazepam would be useful in cases with potential risk of hypoglycemia.

\section{Introduction}

Diabetes mellitus is a common chronic disease. Its prevalence varies in different countries, corresponding to $10 \%$ of the general American population (1) and $7 \%$ of the Brazilian population (2). Its damaging effects on the central nervous system, heart,

\section{Key words}

- Depression

- Antidepressants

- Glucose tolerance

- Diabetes

- Glycemia 
ent diabetic patients. The risk is 15 to $20 \%$ greater than the risk for the general population (4-6). There is a possibility that this percentage is even higher, because depression is underdiagnosed and untreated in many diabetic patients $(5,7,8)$. Depression occurs earlier in life for diabetic patients. In the general population depression signs are present around ages 27 and 35 years, while diabetic patients are depressed by the age of 22 years (9).

The symptoms of depression most commonly related to diabetes are weight loss, psychomotor retardation and tiredness, hypersomnia, feelings of worthlessness, and diminished sexual drive (5). Depression in diabetic patients is proposed to be a result of the changes in life style (diet restriction, chronic treatment, increase in financial expenses, increase in hospitalization frequency) or might be related to physiological changes (blindness, impotence, cognitive damage) (7,10-12). Hyperglycemia may lead to imbalance of the hypothalamo-pituitary-adrenocortical axis and increase cortisol levels, as also observed in depression (13). All of these lines of evidence indicate that depression may be related to diabetes. On the other hand, non-diabetic patients with depressive mood present low glucose tolerance, increased insulin secretion and low sensitivity to insulin (14). Thus, treatment with antidepressant drugs may interfere with blood glucose levels of non-diabetic depressive patients as well as induce changes in blood glucose levels of depressive diabetic individuals.

The treatment of depression is necessary to improve the quality of life of diabetic patients, to increase treatment compliance, and to decrease the risk of microvascular and macrovascular complications $(3,7,15,16)$. Very few studies discuss the effects of antidepressants in diabetic patients $(10,17,18)$. Treatment with antidepressants can directly interfere with blood glucose levels or may interact with hypoglycemic agents. In a re- cent preclinical study it was demonstrated that prolonged treatment with nortriptyline increases blood glucose in diabetic and nondiabetic mice, while fluoxetine and sertraline decrease it (19). Therefore, treatment with antidepressants for diabetic individuals must consider the variability in blood glucose level control at different times and a comparison of the available antidepressant agents is recommended.

In this study, the acute effects of different antidepressant groups on the glucose tolerance test were evaluated in diabetic and nondiabetic rats.

\section{Material and Methods}

\section{Animals}

Male adult Wistar rats $(\mathrm{N}=162)$ raised at the Animal House of the Division of Pharmacology and Toxicology, FFFCMPA, were maintained in a controlled environment (lights on from 7:00 a.m. to 7:00 p.m. and temperature of $22 \pm 2^{\circ} \mathrm{C}$ ) with water and food ad libitum. Twelve hours before the experiments, the animals were fasted. All procedures were performed between 12:00 noon and 15:00 $\mathrm{h}$.

\section{Drugs and solutions}

Glucose $(50 \%, \mathrm{w} / \mathrm{v})$ was prepared with glucose $(\mathrm{D}(+)$ glucose monohydrate; Merck S.A., Rio de Janeiro, RJ, Brazil) dissolved in distilled water. One milliliter of this solution was administered to each rat by gavage.

Streptozotocin $(60 \mathrm{mg} / \mathrm{ml}$; Sigma Chemical Co., St. Louis, MO, USA) was prepared in phosphate buffer, $\mathrm{pH}$ 4.5. Imipramine (5 $\mathrm{mg} / \mathrm{ml}$, Tofranil; Biogalênica, São Paulo, SP, Brazil), moclobemide (30 mg/ml, Aurorix; Produtos Roche Químicos e Farmacêuticos S.A., Rio de Janeiro, RJ, Brazil), clonazepam $(0.25 \mathrm{mg} / \mathrm{ml}$, Rivotril; Roche), fluoxetine $(20 \mathrm{mg} / \mathrm{ml}$, Prozac; Eli Lilly, São Paulo, SP, Brazil) and sertraline (30 mg/ml, Zoloft; 
Pfizer, Guarulhos, SP, Brazil) were diluted in distilled water with $0.05 \%$ Tween 80 added. The control group received only the vehicle. All solutions were prepared immediately before use. Treatments were administered $i p$ in a volume of $1 \mathrm{ml} / \mathrm{kg}$.

\section{Methodology}

Experiment 1. Non-diabetic fasted animals were divided into 6 groups and received control solution (CTR, $\mathrm{N}=9$ ), $5 \mathrm{mg} /$ $\mathrm{kg}$ imipramine (IMI, $\mathrm{N}=10$ ), $30 \mathrm{mg} / \mathrm{kg}$ moclobemide (MOC, $\mathrm{N}=10$ ), $0.25 \mathrm{mg} / \mathrm{kg}$ clonazepam $(\mathrm{CNZ}, \mathrm{N}=10), 20 \mathrm{mg} / \mathrm{kg}$ fluoxetine (FLU, $\mathrm{N}=10$ ) and $30 \mathrm{mg} / \mathrm{kg}$ sertraline (SER, $\mathrm{N}=8$ ). Thirty minutes later, blood was collected by puncture of the distal end of the rat tail. The blood drop was applied to the test zone of the strip for immediate measurement of fasting glycemia with a Glucotrend device (Boehringer Institute, Mannheim, Germany). Glucose solution was administered and blood collections were performed every $30 \mathrm{~min}$ over a period of $120 \mathrm{~min}$. All rats presenting fasting blood glucose levels above $100 \mathrm{mg} / \mathrm{dl}$ were excluded from the sample.

The drug doses were chosen based on their efficacy as antidepressants in previous behavioral studies $(20,21)$.

Experiment 2. In this experiment, animals were divided into two groups: diabetics (STZ, N = 51) and non-diabetics (CTR, N = $51)$. Streptozotocin $(60 \mathrm{mg} / \mathrm{kg})$ was administered ip (22) in a single dose 15 days before the experiment. Diabetes was confirmed using glycosuria and hyperglycemia (glycemia higher than $200 \mathrm{mg} / \mathrm{dl}$ ) as criteria, $72 \mathrm{~h}$ after streptozotocin administration (21). All rats not injected with STZ who presented fasting blood glucose levels above $100 \mathrm{mg} / \mathrm{dl}$ were excluded from the sample.

Animals from both groups were treated with the same doses as used in experiment 1 for vehicle $(\mathrm{N}=8)$, IMI $(\mathrm{N}=9), \operatorname{MOC}(\mathrm{N}=$ $10), \mathrm{CNZ}(\mathrm{N}=8)$, FLU $(\mathrm{N}=8)$ and SER $(\mathrm{N}$
$=8$ ) after a 12-h fast. Blood glucose levels were measured during fasting and $60 \mathrm{~min}$ after glucose overload as described above, after puncture of the distal end of the rat tail and measurement with a Glucotrend device.

\section{Statistical analysis}

The results of each experiment were grouped into a database and analyzed with the Sigma Stat 2.0 Software (Jandel Corporation, San Rafael, CA, USA). Two-way analysis of variance (two-way ANOVA) was applied in experiment 1 considering treatment and time as independent factors and glycemia as the dependent variable. In experiment 2, the effects of diabetic/non-diabetic condition, fasting/overload state and treatment factors on the dependent variable glycemia were evaluated by three-way ANOVA. Also, two-way ANOVA was used for each set of data for the diabetic and nondiabetic animals to check the influence of the factor treatment and time (fasting/overload) on glycemia. The Student-NewmanKeuls test was used to determine the differences among groups. The level of significance was set at $\mathrm{P}<0.05$.

\section{Results}

\section{Experiment 1}

The glucose tolerance test after each treatment showed that IMI and CNZ did not differ from CTR. In these 3 groups, fasting glycemia was about $60 \mathrm{mg} / \mathrm{dl}$ and there was an increase of blood glucose levels to more than $100 \mathrm{mg} / \mathrm{dl}$ at $30,60,90$ and $120 \mathrm{~min}$ after glucose overload $(\mathrm{F}(4,255)=16.732$; $\mathrm{P}<0.001)$.

No change in fasting glycemia was seen after ip administration of antidepressant drugs at doses already shown to induce behavioral effects. MOC, FLU and SER were different from the other treatments $(\mathrm{F}(5,255)=6.432$; $\mathrm{P}<0.001)$ and there was an interaction be- 
Figure 1 - Oral glucose tolerance test of non-diabetic rats treated with antidepressant agents. CTR: Vehicle, IMI: imipramine, MOC: moclobemide, CNZ: clonazepam, FLU: fluoxetine, SER: sertraline. Data are reported as means \pm SEM. $* P<0.001 \mathrm{com}$ pared to fasting; $* * \mathrm{P}<0.001$ compared to other times; $+\mathrm{P}<0.001$ compared to fasting; and $30 \mathrm{~min}$; \#P $<0.001$ compared to other treatments (two-way ANOVA and Student-NewmanKeuls test). tween treatment and time of measurement $(\mathrm{F}(20,255)=2.455 ; \mathrm{P}<0.001)($ Figure 1$)$ MOC significantly increased glycemia at 30 min and FLU increased glycemia at 90 and 120 min after glucose overload. The administration of SER induced a completely different glycemia pattern since it prevented the expected increase in glycemia after glucose overload.

\section{Experiment 2}

The results of experiment 2 (Table 1) showed a significant difference between the

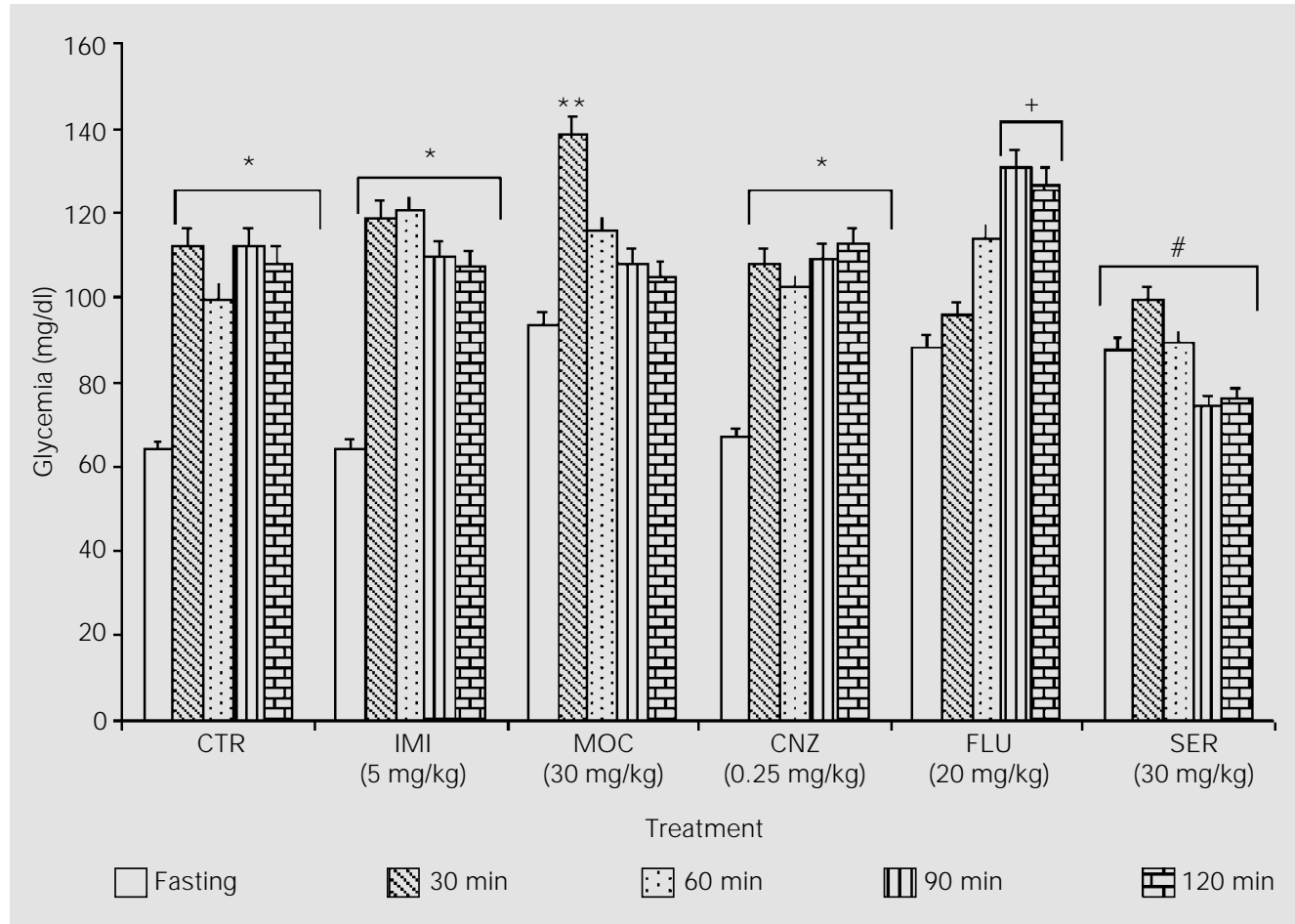

Table 1 - Fasting glycemia and glycemia measured $60 \mathrm{~min}$ after a glucose overload in diabetic and non-diabetic rats treated with different antidepressants.

Notice that diabetic animals present higher glycemias than non-diabetic animals. Data are reported as means \pm SEM. The number of animals is given in parentheses. $* P<0.001$ compared to other treatments; $+P<0.001$ compared to fasting (three-way ANOVA and Student-Newman-Keuls test).

\begin{tabular}{llccc}
\hline & Treatment & Dose $(\mathrm{mg} / \mathrm{kg})$ & Non-diabetic $(\mathrm{mg} / \mathrm{dl})$ & Diabetic $(\mathrm{mg} / \mathrm{dl})$ \\
\hline \multirow{2}{*}{ Fasting } & - & $70.3 \pm 3.5(8)$ & $364.1 \pm 43.9(10)$ \\
& Vehicle & 5 & $64.6 \pm 2.8(9)$ & $402.8 \pm 45.0(7)$ \\
& Imipramine & 30 & $90.0 \pm 4.8(10)$ & $301.1 \pm 49.9(10)$ \\
& Moclobemide & $67.1 \pm 3.3(9)$ & $273.6 \pm 62.7(7)$ \\
& Clonazepam & 0.25 & $89.1 \pm 5.3(10)$ & $313.2 \pm 53.9(9)$ \\
& Fluoxetine & 20 & $57.9 \pm 4.0(9)$ & $414.8 \pm 48.7(9)$ \\
& Sertraline & 30 & $96.7 \pm 3.4^{+}(8)$ & $500.0 \pm 32.9^{+}(10)$ \\
Overload & & $104.8 \pm 6.8^{+}(9)$ & $507.3 \pm 15.8^{+}(7)$ \\
& Vehicle & & $110.9 \pm 5.5(10)$ & $380.2 \pm 37.5^{+}(10)$ \\
& Imipramine & 5 & $125.5 \pm 8.6^{+}(9)$ & $460.9 \pm 31.1^{+}(7)$ \\
& Moclobemide & 30 & $158.3 \pm 14.3^{*}(10)$ & $404.9 \pm 55.0^{+}(9)$ \\
& Clonazepam & 0.25 & $54.9 \pm 15.9^{*}(9)$ & $405.6 \pm 61.2^{+}(9)$
\end{tabular}




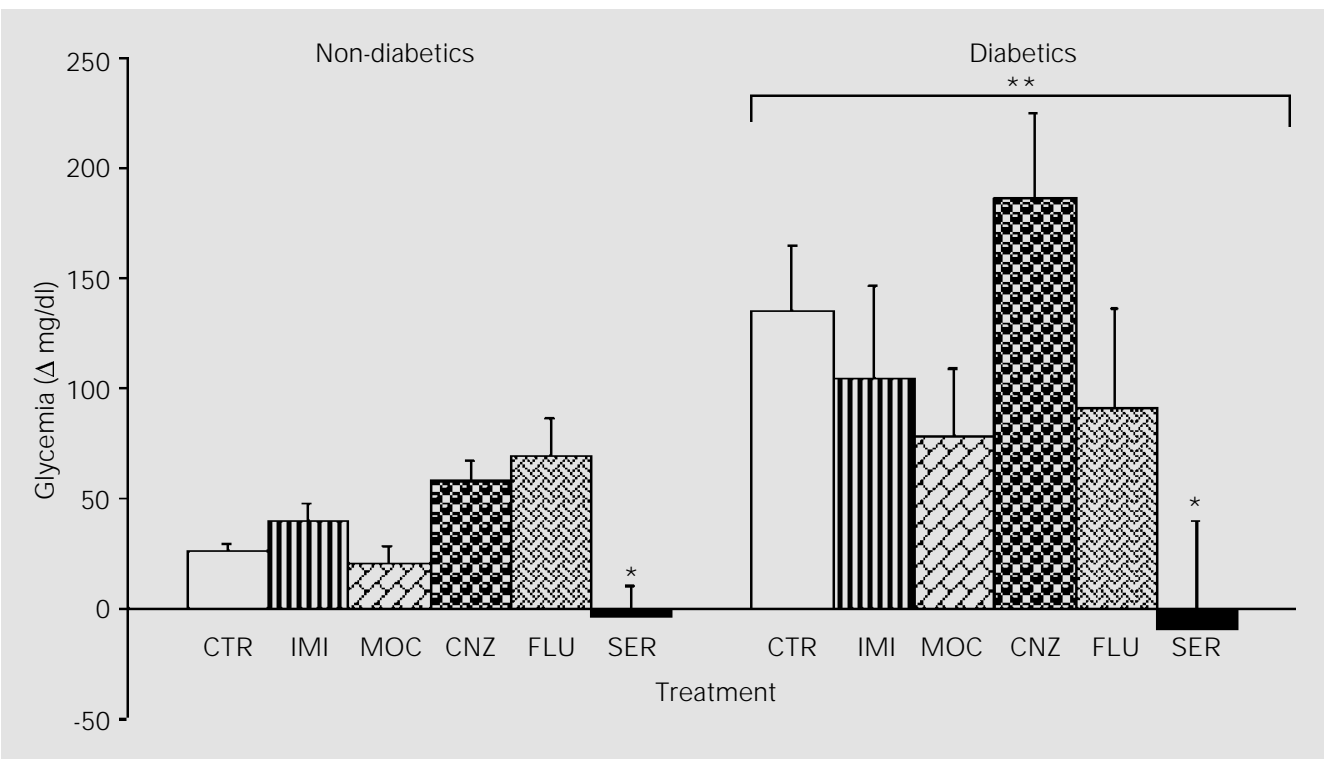

non-diabetic and the diabetic groups of rats $(\mathrm{F}(1,186)=480.12 ; \mathrm{P}<0.001)$ and between fasting and overload condition $(\mathrm{F}(1,186)=$ $23.29 ; \mathrm{P}<0.001)$, and an interaction on nondiabetic/diabetic factor and treatment $(\mathrm{F}(5,186)=3.33 ; \mathrm{P}=0.007)$.

Analysis of data from non-diabetic animals showed a significant difference between fasting and overload $(\mathrm{F}(1,96)=56.86$; $\mathrm{P}<0.001)$. Antidepressant treatment modified glycemia $(\mathrm{F}(5,96)=15.94 ; \mathrm{P}<0.001)$ and an interaction was observed $(\mathrm{F}(5,96)=$ 5.52; $\mathrm{P}<0.001)$. As seen in experiment 1 , groups treated with vehicle, IMI, CNZ and FLU presented higher 60-min overload glycemia compared to the fasting condition. For the groups treated with MOC or SER no difference was observed between fasting and overload glycemia. FLU significantly increased overload glycemia and SER significantly decreased it when compared to overload glycemia plus vehicle. None of the treatments changed fasting glycemia values in non-diabetic rats.

Considering the differences between overload and fasting glycemia, a significantly higher delta value was detected for diabetic animals $(\mathrm{F}(1,94)=15.247 ; \mathrm{P}<0.001)$ and treatment with SER prevented the increase of blood glucose levels after overload both in diabetic and non-diabetic rats $(\mathrm{F}(5,94)=$ 4.398; $\mathrm{P}=0.001)$ (Figure 2).

\section{Discussion}

Our results demonstrate that different groups of antidepressant drugs cause diverse changes in glycemia in diabetic and non-diabetic rats, mostly after glucose overload. The most important changes in glycemia in nondiabetic rats occurred after the administration of FLU, which caused an increase in glycemia during the post-oral glucose phase of the test. The maintenance of blood glucose levels during the overload test induced by SER was impressive both in non-diabetic and diabetic animals and showed that SER has a different action profile compared to the other treatments. Interestingly, SER did not cause hypoglycemia with the antidepressive dose tested.

Depression treatment in diabetes is important because it improves the quality of life, increases treatment compliance, and permits patients to achieve better glycemia control, which may reduce long-term complications and emergencies. Depending on depression intensity, pharmacological intervention is obligatory. Antidepressants might
Figure 2 - Differences between glycemias measured during fasting and $60 \mathrm{~min}$ after the glucose overload. Diabetic and non-diabetic rats were treated with different antidepressants. CTR: Vehicle, IMI: imipramine, MOC: moclobemide, CNZ: clonazepam, FLU: fluoxetine, SER: sertraline. Data are reported as means \pm SEM. $* \mathrm{P}<0.001 \mathrm{com}$ pared to other treatments: $* * P<0.001$ compared to nondiabetics (two-way ANOVA and Student-Newman-Keuls test). 
also be used as a prophylactic treatment for diabetic patients $(7,11,17)$. Therefore, the effects on blood glucose control caused by antidepressant drugs and their interaction with oral hypoglycemic agents or insulin need to be known. As was observed in several other studies, the classical antidepressant (23) and monoamine oxidase (MAO) inhibitors most frequently induce hyperglycemia $(18,24)$ in patients and other animal species $(19,25)$. In the clinical setting, adjustment of doses of hypoglycemic agents might be necessary (26-29). In the present study, the changes in glycemia induced by MOC, a MAO inhibitor, were found to be ephemeral, occurring only immediately after MOC administration.

A very effective and frequently used antidepressant class is that of selective serotonin reuptake inhibitors (30), considered to have few adverse effects (18). However, it is recognized that fluoxetine increases insulin receptor sensitivity (31) and competes with sulfonylurea for cytochrome P-450 metabolism (29), requiring adjustment of the doses of insulin or hypoglycemic agents to avoid hypoglycemia $(32,33)$. On the other hand, non-insulin-dependent diabetic patients who are treated with fluoxetine show a consistent reduction in carbohydrate consumption and weight loss associated with a decrease in HbA1c $(34,35)$. Ultimately, sertraline may be a better agent for depression treatment in diabetic patients (36). In this preclinical study, fluoxetine induced peaks of increased glycemia while sertraline prevented the increase in glycemia after glucose overload. Further studies are needed to determine whether this acute effect will be still demonstrable after long-term treatment, as seen in mice (19). The explanation for the effect seen after sertraline may be associated with an increase in plasma insulin concentration after glucose overload in streptozotocin-induced diabetic and non-diabetic rats, as evidenced in a preliminary study undertaken in our laboratory. However, a reduction in intestinal glu- cose absorption or an increase in peripheral insulin receptor sensitivity cannot be ruled out and needs further study. Despite the antidepressant group classification based upon their mechanisms of action, several differences in specificity occur among the agents. Fluoxetine and sertraline are selective serotonin reuptake inhibitors, but sertraline is a more powerful serotonin and dopamine reuptake inhibitor than fluoxetine, while fluoxetine is more potent as an antagonist of 5- $\mathrm{HT}_{2}$ receptors (37). It is still necessary to clarify whether the neurochemical differences are responsible for the differences in effects seen in the present study.

Other neurotransmitter systems might participate in depression (38). Alprazolam has been demonstrated to be effective as an antidepressant $(5,39)$. In preclinical studies, clonazepam has shown an antidepressant effect in streptozotocin-induced diabetic rats (21). Diazepam, another benzodiazepine agent, increases fasting glycemia and decreases glucose overload glycemia in diabetic rats (40). Thus, there is interest in the present demonstration that clonazepam does not change the fasting and overload glycemic levels in diabetic and non-diabetic rats, confirming that this agent is a good alternative for the treatment of depression in diabetics.

Depression in diabetic patients must be treated or prevented by first using simple and non-pharmacological interventions for improving quality of life. When antidepressants are deemed necessary, sertraline seems to be a good first choice agent (36) due to its well-documented stabilization of glucose levels. As a second choice to avoid disturbances in glycemia, clonazepam seems to be a safe antidepressant drug for diabetics.

\section{Acknowledgments}

The authors thank AAPEFATO (Associação de Amparo à Pesquisa em Farmacologia e Toxicologia). 


\section{References}

1. Davis SN \& Granner DK (1996). Insulina, fármacos hipoglicemiantes orais e a farmacologia do pâncreas endócrino. In: Hardman JG \& Limbird LE (Editors), Goodman \& Gilman: As Bases Farmacológicas da Terapêutica. 9th edn. Guanabara Koogan, Rio de J aneiro.

2. Malerbi D \& Franco LJ (1992). Brazilian Cooperative Group on the study of diabetes prevalence. Multicenter study of the prevalence of diabetes mellitus and impaired glucose tolerance in the urban Brazilian population aged 30-69 years. Diabetes Care, 15: 509-516.

3. Spis K, Pietschmann P \& Prager R (1995). A program to reduce onset distresses in unselected type I diabetic patients: effects on psychological variables and metabolic control. European J ournal of Endocrinology, 132: 580-586.

4. Lilliker SL (1980). Prevalence of diabetes in a manic-depressive population. Comparative Psychiatry, 21: 270-275.

5. Lustman PJ, Griffith LS, Gavard JA \& Clouse RE (1992). Depression in adults with diabetes. Diabetes Care, 15: 16311639.

6. Gavard J A, Lustman PJ \& Clouse RE (1993). Prevalence of depression in adults with diabetes. Diabetes Care, 16: 11671178.

7. Wredling RAM, Theorell PGT, Roll HM, Lins PES \& Adamson UKC (1992). Psychosocial state of patients with IDDM prone to recurrent episodes of severe hypoglycemia. Diabetes Care, 15: 518-521.

8. Fifer SK, Mathias SD, Patrick DL, Mazonson PD, Lubeck DP \& Buesching DP (1994). Untreated anxiety among adult primary care patients in a health maintenance organization. Archives of General Psychiatry, 51: 740-750.

9. Lustman PJ, Griffith LS \& Clouse RE (1988). Depression in adults with diabetes: results of 5-year follow-up study. Diabetes Care, 11: 605-612.

10. Lustman PJ, Amado $\mathrm{H} \&$ Wetzel RD (1983). Depression in diabetics: a critical appraisal. Comparative Psychiatry, 24: 6574.

11. Lustman PJ, Griffith LS, Freedland KE, Kissel SS \& Clouse RE (1998). Cognitive behavior therapy for depression in type 2 diabetes mellitus. A randomized, controlled trial. Annals of Internal Medicine, 129: 613-621.

12. Lowe LP, Tranel D, Wallace RB \& Welty TK (1994). Type II diabetes and cognitive function. Diabetes Care, 17: 891-896.
13. Cameron OG, Kronfol Z, Greden JF \& Caroll BJ (1984). Hypothalamic pituitary adreno-cortical activity in patients with diabetes mellitus. Archives of General Psychiatry, 41: 1090-1095.

14. Okamura F, Tashiro A, Utsumi A, Imai $T$, Suchi T \& Hongo M (1999). Insulin resistance in patients with depression and its changes in the clinical course of depression: a report on three cases using the minimal model analysis. Internal Medicine, 38: 257-260.

15. Lustman PJ , Clouse RE \& Freedland KE (1998). Management of major depression in adults with diabetes: implications of recent clinical trials. Seminars in Clinical Neuropsychiatry, 3: 102-114.

16. Sachs G, Spiess K \& Moser G (1991). Glycosylated hemoglobin and diabetes self-monitoring (compliance) in depressed and non-depressed type I diabetes patients. Psychotherapie, Psychosomatik, Medizinische Psychologie, 41: 306-312.

17. Lustman PJ , Griffith LS, Freedland KE \& Clouse RE (1997). The course of major depression in diabetes. General Hospital Psychiatry, 19: 138-143.

18. Goodnick PJ , HenryJ H \& Buki VM (1995). Treatment of depression in patients with diabetes mellitus. J ournal of Clinical Psychiatry, 56: 128-136.

19. Erenmemisoglu A, Ozdogan UK, Saraymen T \& Tutus A (1999). Effect of some antidepressants on glycaemia and insulin levels of normoglycaemic and alloxan-induced hyperglycaemic mice. J ournal of Pharmacy and Pharmacology, 51: 741743.

20. Ferigolo $M$, Barros HMT, Marquardt AR \& Tannhauser M (1998). Comparison of behavioral effects of moclobemide and deprenyl during forced swimming. Pharmacology and Biochemical Behavior, 60: 431-437.

21. Gomez R \& Barros HMT (2000). Ethopharmacology of the antidepressant effect of clonazepam in diabetic rats. Pharmacology and Biochemical Behavior, 66: 329335.

22. Like AA \& Rossini AA (1976). Streptozotocin-induced pancreatic insulitis: new model of diabetes mellitus. Science, 193: 415-417.

23. Lustman PJ, Griffith LS, Clouse RE, Freedland KE, Eisen SA, Rubin EH, Camey RM \& McGill J B (1997). Effects of nortriptyline on depression and glycemic control in diabetes: results of a double blind, placebo-controlled trial. Psychosomatic Med- icine, 59: 241-250.

24. Kaplan SM, Mass J W, Pixley J M \& Ross D (1960). Use of imipramine in diabetes. Effects on glycosuria and blood sugar levels. J ournal of the American Medical Association, 174: 511-517.

25. Gupta B, Awasthi A \& J aju BP (1992). Effect of acute and chronic imipramine treatment on glucose homeostasis. Indian J ournal of Medical Research, 96: 65-71.

26. Cooper AJ \& Ashcroft G (1963). Potentiation of insulin hypoglycemia by MAOI antidepressant drugs. Lancet, 1: 407-409.

27. Potter WZ, Zaharko DS \& Beck LV (1969). Possible role of hydrazine group in hypoglycemia associated with the use of certain monoamine-oxidase inhibitors (MAOIs). Diabetes, 18: 538-541.

28. Bressler R \& J ohnson D (1992). New pharmacological approaches to therapy of NIDDM. Diabetes Care, 15: 792-805.

29. Takhar J \& Williamson P (1999). Hypoglycemia associated with high doses of sertraline end sulfonylurea compound in a non-insulin-dependent diabetes mellitus patient. Canadian J ournal of Pharmacology, 6: 12-14.

30. Cohn J B \& Wilcox C (1985). A comparison of fluoxetine, imipramine, and placebo in patients with major depressive disorder. J ournal of Clinical Psychiatry, 46: 26-31.

31. Maheux P, Ducros F, Bourque J, Garon J $\&$ Chiasson JL (1997). Fluoxetine improves insulin sensitivity in obese patients with non-insulin-dependent diabetes mellitus independently of weight loss. International J ournal of Obesity and Related Metabolic Disorders, 21: 97-102.

32. Potter Van Lonn BJ , Radder J K, Frolich M Krans HM, Zwinderman AH \& Meinders AE (1992). Fluoxetine increases insulin action in obese non-diabetic and obese non-insulin-dependent diabetic individuals. International J ournal of Obesity and Related Metabolic Disorders, 16: 79-85.

33. True BL, Perry PJ \& Burns EA (1987). Profound hypoglycemia with the addition of a tricyclic antidepressant to maintenance sulfonylurea therapy. American J ournal of Psychiatry, 144: 1220-1221.

34. Daubresse J C, Kolanowski J , Krzentowski G, Kutnowski M, Scheen A \& Van Gaal L (1996). Usefulness of fluoxetine in obese non-insulin-dependent diabetics: a multicenter study. Obesity Research, 4: 391396.

35. O'Kade M, Wiles PG \& Wales J K (1994). Fluoxetine in the treatment of obese type 2 diabetic patients. Diabetes Medicine, 
11: 105-110.

36. Goodnick PJ, Kumar A, Henry J H, Buki VM \& Goldberg RB (1997). Sertraline in coexisting major depression and diabetes mellitus. Psychopharmacology Bulletin, 33: 261-264.

37. Richelson I (1996). Synaptic effects of antidepressants. J ournal of Clinical Psycho- pharmacology, 16 (Suppl 2): 1-9.

38. Petty $F$ (1997). GABA and mood disorders: a brief review and hypothesis. J ournal of Affective Disorders, 34: 275-281.

39. J onas J M \& Cohon MS (1993). A comparison of the safety and efficacy of alprazolam versus other agents in the treatment of anxiety, panic and depression: a review of the literature. J ournal of Clinical Psychiatry, 54: 25-45.

40. Gomez R, Asnis N, Tannhauser SL \& Barros HMT (1999). GABA agonists differentially modify blood glucose levels of diabetic rats. J apanese J ournal of Pharmacology, 80: 327-331. 